\title{
ARDS Case Treated With ECMO
}

Çıkar Çatışması: Çıkar çatışması yoktur.

Finansal Destek: Bu çalışma, herhangi bir fon tarafından desteklenmemiștir.

Hasta Onamı: Hastalardan aydınlatılmış onam alınmıştır.
Conflict of Interest: There is no conflict of interest.

Funding: The authors declared that this study has received no financial support.

Informed Consent: Informed consent was obtained from the patients.

Cite as: Tekir YIImaz E, Demiriz Gulmez D. ECMO ile tedavi edilen ARDS olgusu. GKDA Derg. 2020;26(4):272-6.

öz

Akut Respiratuar Distres Sendromu (ARDS) bilateral radyolojik infiltrasyon ve hipoksemik solunum yetmezliği ile karakterizedir. Kırk sekiz yaşında ev hanımı pnömoni nedeniyle göğüs hastanesinde tedavi edilirken solunum sıkıntısı nedeniyle entübe edilmiş. Üç kez kardiyak arrest gelişen hastaya müdahale edilmiş yaklaşık $15 \mathrm{dk}$. CPR uygulanmış. Hasta 3. basamak yoğun bakıma kabul edildiğinde ilk kangazında ph'sı 6.9'du ve mix asidozu mevcuttu. Hasta SIMV modda MV'e bağlandı. Solunum sistemi oskültasyonunda bilateral ralleri mevcuttu. PAAC grafisinde atılmış pamuk manzarası olan hastaya ARDS ön tanısı koyuldu. infeksiyon hastalıkları ile konsulte edilen hastanın mevcut antibiyoterapisine zyvoxid 2x1 eklendi (avelox $1 \times 1$ meronem 2x1). Hastanın takiplerinde, kültürlerinde herhangi bir üreme saptanmadı. Hastanın giriş parametreleri WBC 45000 CRP: 11 mg/dL Sedimantasyon: 84 mg/dL. Hastanın 2 gün koruyucu ventilasyon stratejisiyle mekanik ventilatörde takip edilmesine rağmen $\mathrm{PaO}_{2}$ / $\mathrm{FiO}_{2}<100$ olması, kan gazı değerlerinin düzelmemesi üzerine ECMO tedavisi kararı verildi. Beş gün ECMO tedavisi uygulandı. Ardından extübe edilen hasta gögüs hastalıklarına devredilip komplikasyonsuz servise alındı.

Anahtar kelimeler: ARDS, ekstrakorporeal mebranöz oksijenizasyon, pnömoni

\section{ABSTRACT}

Acute Respiratory Distress Syndrome (ARDS) is characterized with diffuse bilaterat radiologic infiltration, and a hypoxemic respiratory failure. A 48-year-old housewife hospitalized in a chest diseases hospital with the diagnosis of pneumonia was intubated for increased respiratory distress. The patient, who developed cardiac arrest three times underwent CRP for nearly 15 minutes. When she was admitted to intensive care unit of a tertiary healthcare institute, severe acidosis was detected in her first arterial blood gas sample (ph 6.9). Bilateral rales were heard in respiratory system auscultation and "cotton wool spots" were observed on her PA chest X-ray and initial diagnosis of ARDS was made. The patient was consulted with the department of infectious diseases, and zyvoxid $2 \times 1$ (avelox $1 \times 1$ meronem $2 \times 1$ ) were added to her antibiotherapy. The patient's admission parameters were as follows: WBC 45000/ $\mathrm{mm}^{3}$ CRP: $11 \mathrm{mg} / \mathrm{dL}$ sedimentation: $84 \mathrm{mg} / \mathrm{dL}$. Although the patient was followed up on a mechanical ventilator with a protective ventilation strategy for 2 days, ECMO treatment was decided because $\mathrm{PaO}_{2} /$ $\mathrm{FiO}_{2}<100$ and blood gas values did not improve. ECMO treatment was applied for 5 days. Then, the patient was extubated and transferred to the service without complications.

Keywords: ARDS, extracorporeal membranous oxygenation, pneumonia
Received/Geliş: 13.10 .2020

Accepted/Kabul: 19.11 .2020

Published Online/Online yayın: 31.12.2020

Duygu Demiriz Gülmez Giresun Üniversitesi Prof. Dr. İlhan Özdemir Eğitim Araştrrma Hastanesi Anesteziyoloji ve Reanimasyon Anabilim Dalı Giresun, Türkiye duygudemiriz@hotmail.com ORCID: 0000-0002-0874-7067

E. Tekir Yılmaz 0000-0001-8631-2520 Giresun Üniversitesi Prof. Dr. İhan Özdemir Eğitim Araştırma Hastanesi Anesteziyoloji ve Reanimasyon $A B D$ Giresun, Türkiye

${ }^{\S} B u$ olgu sunumu, 2020 GKDA ve YB Kongresi'nde Dr. Duygu Demiriz Gülmez tarafindan online olarak sunulmuştur.

\section{Giriş}

Akut Respiratuar Distres Sendromu (ARDS) pulmoner damar geçirgenliğinin arttı̆̆ı, havalanan akciğer dokusunun azaldığı, her 2 akciğeri de tutan diffüz ve inflamatuar bir akciğer hasarıdır. ARDS tanı kriterleri 1994 yılında Amerikan Toraks Derneği ve Avrupa Yoğun Bakım dernekleri tarafından düzenlenen ortak bir top- lantıda belirlenmiştir. Üzerinde çeşitli değişiklikler yapılmış ve 2012 yılında Berlin tanımlaması olarak ortak uzlaşı raporları ile açıklanmıştır. Buna göre; bir hafta içinde ortaya çıkan yeni veya kötüleşen solunum sıkıntısı, radyolojik olarak efüzyon, kollabs veya nodül ile açıklanamayan opasite, solunum sıkıntısının kalp yetmezliği veya hipervolemiyle açıklanamaması ve $\mathrm{PaO}_{2} /$ $\mathrm{FiO}_{2}$ oranı $\leq 300$ olan her hasta ARDS kabul edilir ${ }^{[1,2]}$. 
Geleneksel akciğer koruyucu mekanik ventilasyon uygulamaları ile düzelme izlenmeyen ağır ARDS olgularında ekstrakorporeal membran oksijenasyonu (ECMO) alternatif bir tedavi seçeneği olabilir. Bu makalede, pnömoni nedeniyle ağır ARDS gelişen yoğun bakıma yatışına kadar 3 kez kardiyak arrest geçiren ve ECMO ile tedavi edilen bir olgu sunulmuştur.

\section{OLGU}

Kırk sekiz yaşında ev hanımı olan olgunun 1 hafta önce öksürük yakınması başlamış, acil servise başvuran hastaya 4. kuşak kinolon (moksifloxasin) tedavisi verilmiş. Yakınmaları geçmeyen hasta 2 gün sonra solunum sıkıntısı ile yine acil servise gelmiş. Tomografisinde bilateral infiltrasyonları olması nedeniyle göğüs hastanesine gönderilmiş. Yoğun bakım yatışı yapılan hastanın tedavisine meropenem $2 \times 1$ eklenmiş. íki gün sonra solunum sıkıntısı şiddetlenen hasta entübe edilip mekanik ventilatöre bağlanmış. Sonrasında kardiyak arrest gelişen hastaya $3 \mathrm{dk}$. CPR uygulanmış ve hasta hastanemize sevk edilmiş, sevk sırasında cankuranda yeniden kardiyak arrest gelişen hastaya $10 \mathrm{dk}$. daha CPR uygulanmış. Acil servise kabulünde 3. kardiyak arresti gelişen hastaya $3 \mathrm{dk}$. daha CPR yapılmış, hasta yoğun bakım ünitemize kabul edildi. Özgeçmişinde kalp yetmezliği ve DM olan hastanın soygeçmişinde bir özellik yoktu. Kabulünde kan gazında $\mathrm{Ph} 6.9, \mathrm{PCO}_{2} 73.8 \mathrm{mmHg}, \mathrm{PO}_{2}$ $39 \mathrm{mmHg}, \mathrm{HCO}_{3}$ act $16.2 \mathrm{mEq} / \mathrm{L}$, Laktat $10.05 \mathrm{mmol} / \mathrm{L}$ di. Hasta SIMV-P modda mekanik ventilatöre bağlandı. Laboratuvar tetkikinde üre $54 \mathrm{mg} / \mathrm{dL}$, kreatinin 1.25 mg/dL, ALT 61, AST 108 U/L di. CRP'si 11.11 mg/ $\mathrm{dL}$, sedim $84 \mathrm{mg} / \mathrm{dl}$ di. WBC 45.000, hemoglobin $10.9 \mathrm{~g} / \mathrm{dL}$ di.

Hastaya santral kateterizasyon ve arter monitörizasyonu yapılıp norepinefrin inf'u başlandı. Bir saat sonra alınan arteryel kan gazı değerleri (AKG) $\mathrm{pH}$ : 7,42, parsiyel oksijen basıncı $\left(\mathrm{PaO}_{2}\right) 73 \mathrm{mmHg}$, parsiyel karbondioksit basıncı $\left(\mathrm{PaCO}_{2}\right) 48 \mathrm{mmHg}$ 'dı. Akciğer radyogramında sağda orta ve alt zonlarda yaygın radyoopak görünüm solda tüm zonlarda

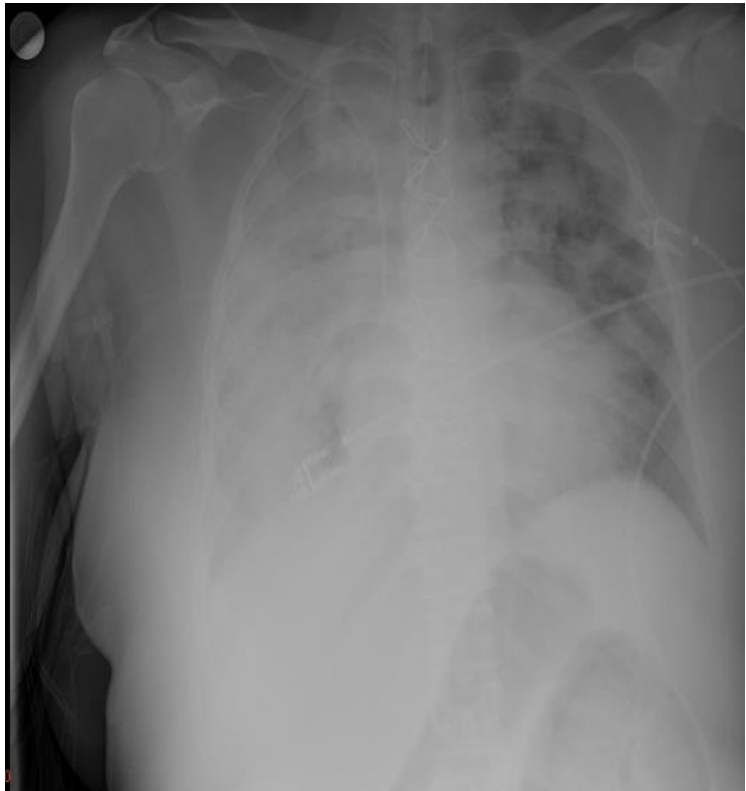

Şekil 1. ECMO öncesi.

yamasal radyoopasiteler görüldü (Şekil 1).

Hızlı progresyon gösteren hastaya ampirik olarak antiviral tedavi de başlandı. Çekilen tomografisinde yaygın, buzlu camı andıran diffüz infiltrasyonlar görüldü. Kan gazı değerlerinin bozulması üzerine \%100 $\mathrm{FiO}_{2}$ uygulanarak, 14 PEEP değerine kadar çıkıldı. İzleminin 2. gününde IMV ayarları değiştirilerek destek artırıldı. \%100 FiO 20 PEEP, \%100 MV desteğinde iken alınan $A K G^{\prime}$ da $\mathrm{pH}: 7,30, \mathrm{PaO}_{2}: 49 \mathrm{mmHg}$, $\mathrm{PaCO}_{2}: 64 \mathrm{mmHg}$, HCO3: 20 meq/L, $\mathrm{SaO}_{2}: \% 90, \mathrm{PaO}_{2} /$ $\mathrm{FiO}_{2}: 49$ olarak saptandı. Bu arada recruitment manevrası 2 saatte bir aralıklı olarak (RM, atelektatik akciğer alanlarını açmak için hava yolu basıncını bir süreliğine devamlı olarak yükseltmektir. Hastamızda 15 sn süre ile $45 \mathrm{cmH}_{2} \mathrm{O}$ basınç sınırlamalı RM yaptık.) uygulandı, oksijenasyonda kısa süreli düzelme izlendi. Hastaya ECMO tedavisi kararı verildi. Hastaya femoral bölgeden veno-venöz kanülasyon uygulandı. ECMO cihazında \%100 $\mathrm{FiO}_{2}$, 4 It/dk. akım hızı ayarlandı. ECMO tedavisi süresince aktive parsiyel tromboplastin zamanı (aPTT) normalin 1-1,5 katı düzeyinde olacak şekilde heparin infüzyonu yapılarak takibe alındı. Hastanın PA AC ile takiplerinde belirgin düzelme izlendi (Şekil 2, 3). Mekanik ventilatör ayarları P-SIMV modunda $\mathrm{FiO}_{2} \% 40$, PEEP 9 olacak 


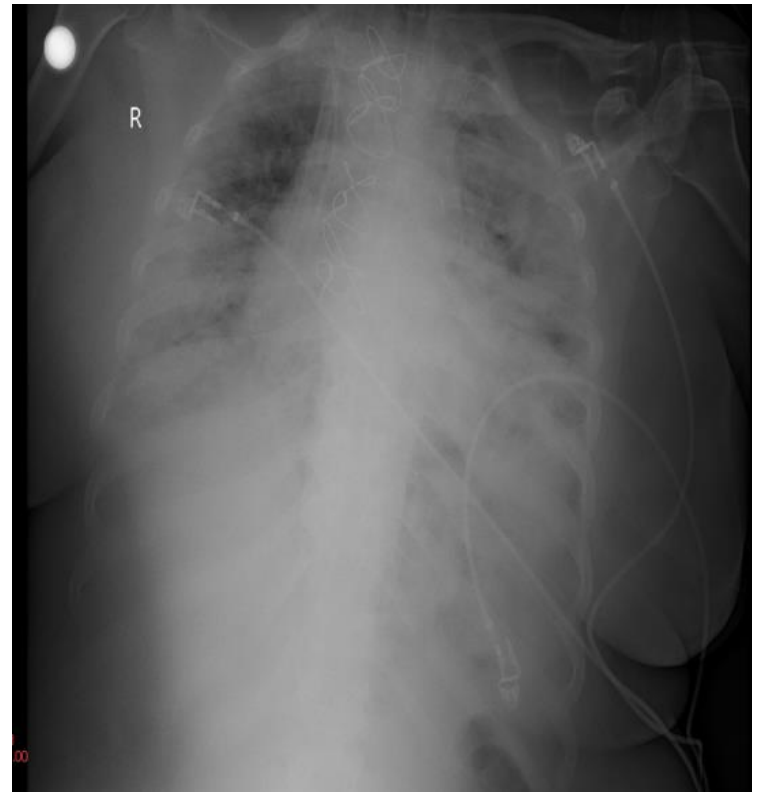

Şekil 2. ECMO sonrası 1. gün.

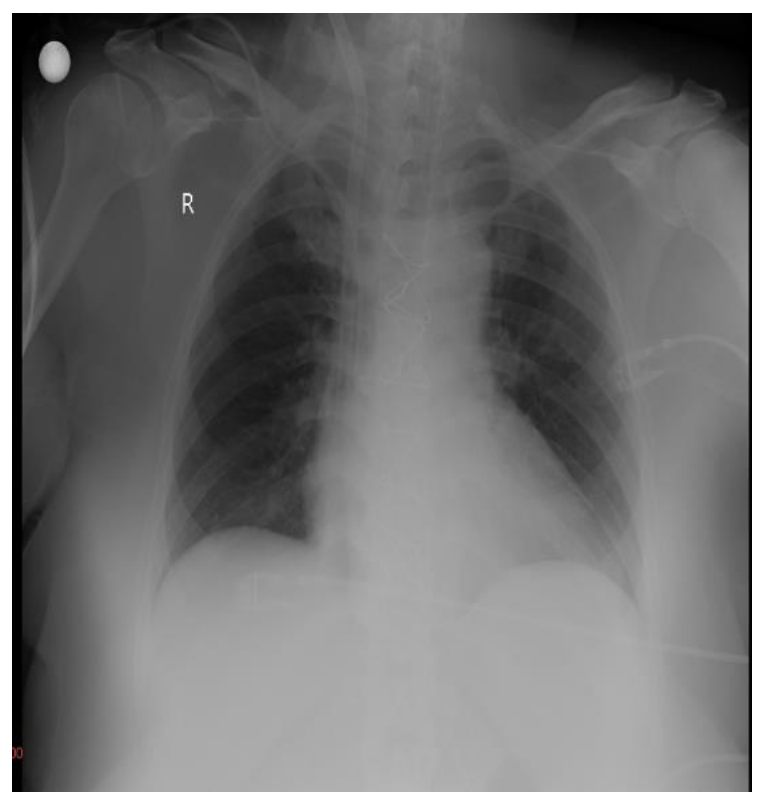

Şekil 4. Kontrol grafisi.

şekilde azaltıldı. Klinik ve laboratuvar olarak stabil seyreden olguda ECMO tedavisi $\mathrm{FiO}_{2}$, kademeli olarak akım hızı azaltılarak 5. gününde sonlandırıldı. Kateter çekildikten sonra ACT 153 olması üzerine protamin yapılmadı. ECMO tedavisi sonlandırıldıktan sonra hasta bir gün daha mekanik ventilatörde izlendi. P-SIMV modunda $\mathrm{FiO}_{2} \% 40$, PEEP 6, solu-

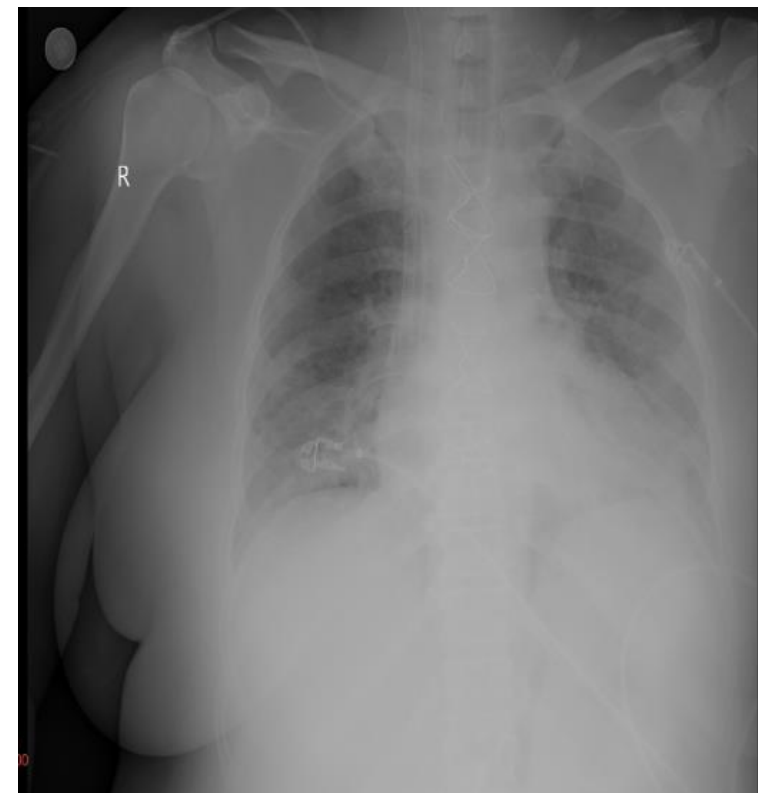

Şekil 3. ECMO sonrası 3. gün.

num sayısı 14 ile alınan AKG değerleri pH: 7.40, $\mathrm{PaO}_{2}: 143.4 \mathrm{~mm} / \mathrm{Hg}, \mathrm{PaCO}_{2}: 47 \mathrm{~mm} / \mathrm{Hg}, \mathrm{SaO}_{2}: \% 99$ ve $\mathrm{PaO}_{2} / \mathrm{FiO}_{2}$ : 357 saptanan olgu yatışının 7. gününde ekstübe edilerek nazal kanül yoluyla oksijen desteğinde izlendi.

Hasta nöroloji ile konsulte edildi çekilen difüzyon MR'ında bilateral serebellar sekel belirlendi. Nörolojik muayenesinde motor ve duyu defisiti yoktu, Glaskow $15^{\prime}$ ti tedavisine ecopirin eklenerek poliklinik kontrolü önerildi. Çekilen kontrol akciğer grafisinde tama yakın regresyon izlendi (Şekil 4). Olgu, yoğun bakım yatışının 10. günü göğüs hastalıkları servisine nakil edildi. Hasta şifa ile taburcu edildi.

\section{TARTIŞMA}

ARDS'li hastalarda mekanik ventilasyon yaşam kurtarıcı olsa da, ventilatör kaynaklı akciğer hasarı ile ilişkilidir. Bu komplikasyon iki temel mekanizmayla açıklanmaya çalışılmıştır; yüksek hava yolu basınçları (barotravma) ve yüksek tidal volümler nedeniyle oluşabilen aşırı döngüsel distansiyon ve her soluk alışta meydana gelen döngüsel kollaps ve hava yolu birimlerinin yeniden açılması (atelektotravma). 
Dahası, mekanik ventilasyon uygulaması sonrasında alveoler hücrelerin distansiyonu, yırtılması veya nekrozu pulmoner ve sistemik enflamatuvar yanıt riskini arttırabilir (biotravma) ${ }^{[3]}$.

Düşük tidal hacim ve yüksek PEEP tedavisi günümüzde ARDS mekanik ventilasyon stratejisi olarak kabul edilmektedir ${ }^{[4,5]}$. ARDS olgularında prone pozisyon recruitment manevrası, yüksek frekanslı ventilasyon (HFO) ve ECMO başlıca kullanılan tedavi yöntemleridir ${ }^{[6,7]}$. ECMO yeni doğan ve çocuklarda kardiyorespiratuar yetmezlik tedavisinde 40 yıldır kullanılmaktadır. Yetişkinlerde kullanımı 1970'lerin başında bildirilmiş, 2009 yılındaki influenza epidemisi sonrasında oran giderek artmıştır.

ECMO uygulaması sırasında çift lümenli kanül venovenöz (VV) ya da venoarteryel (VA) olarak hastaya yerleştirilmektedir. Hastadan gaz değişim ünitesine belli akım hızında kan akışı sağlanarak kan oksijenlendirilmekte, oksijenlenmiş kan hastaya geri gönderilmektedir ${ }^{[8]}$. Hemodinamik olarak destek gereken olgularda venoarteryel kanülasyon önerilmektedir ${ }^{[8]}$. Hastamıza venovenöz kanülasyon uygulandı.

ECMO uygulaması için en geçerli endikasyon geleneksel akciğer koruyucu mekanik ventilasyon stratejileriyle tedavi edilen hastalarda tedaviye yanıtsılıktır. Ekstrakorporal Yaşam Destek Organizasyonu (Extracorporeal Life Support Organization; ELSO) kayitlarında hasta seçimi için bazı kriterler mevcuttur. Venö-venöz (VV) ECMO için; Herhangi bir nedenden kaynaklanan respiratuar yetmezlik ve $>\% 80$ mortalite riski (6 saat ve üzerinde optimal tedaviye rağmen, $\mathrm{FiO}_{2}$ $>\% 90, \mathrm{PaO}_{2} / \mathrm{FiO}_{2}<100$ ), akciğer transplantasyon listesindeki hasta için entübasyon gereksinimi ${ }^{\left[{ }^{[0]}\right.}$, mekanik ventilasyonda yüksek plato basıncına rağmen $(>30 \mathrm{~cm}$ $\left.\mathrm{H}_{2} \mathrm{O}\right) \mathrm{CO}_{2}$ retansiyonu olması ${ }^{[10]}$, şiddetli hava kaçağı sendromu (air leak syndrome), optimal tedaviye yanıt vermeyen ani kardiyak veya respiratuar kollaps sayılabilir. Hastaya 7 günün üzerinde yüksek ayarlarda (yüksek peep ve $\mathrm{FiO}_{2}$ ) mekanik ventilasyon uygulanması, tanıksız kardiyak arrest (hastanın nekadar süre hipoksiye maruz kaldığının bilinmemesi), immünsüpresyona neden olucak herhangi bir patolojinin varolması ise en başta gelen kontrendikasyonlarındandır.

Hastamızda; $\mathrm{PaO}_{2} / \mathrm{FiO}_{2}$ 49, optimal tedaviye (düşük tidal volüm ve yüksek frekans ve yüksek peep değerleri, RM) rağmen yükselmeyen $\mathrm{SPO}_{2}$ ve $\mathrm{CO}_{2}$ retansiyonu nedeniyle ECMO düşünülmüştür.

ECMO komplikasyonları kanama, koagülopati, trombositopeni, mekanik komplikasyonlar olarak özetlenebilir. En çok görülen komplikasyon kanamadır. Hastamız ECMO'una bağlı herhangibir komplikasyon gözlenmeksizin takip edilmiştir. Difüzyon MR'ında bilateral serebellar defekt mevcuttur fakat kliniğe yansıyan patolojik bulgusu olmamıştır.

ECMO tedavisinin erken başlanması ile yaşam arasında ilişki olduğu düşünülmektedir. İleri düzeyde IMV desteği sonrası akciğer hasarı oluştuktan sonra ve de endorgan disfonksiyonları başladıktan sonra kullanımı önerilmemektedir. Bu nedenle ARDS'nin erken evresinde kriterleri sağlayan hastalarda başlanması uygun olabilir. Hastamızda mekanik ventilasyonun 3. günü ECMO kararı verilip başlanmıştır. Üç kez kardiyak arrest olup ECMO tedavisi sonucu komplikasyonsuz taburcu olan hastanın kliniğimiz açısından başarıIı bir olgu yönetimi olduğunu düşünmekteyiz.

\section{KAYNAKLAR}

1. Bernard GR, Artigas A, Brigham KL, et al. The AmericanEuropean Consensus Conference on ARDS:definitions, mechanisms, relevant outcomes, and clinical trial coordination. AmJ Respir Crit Care Med. 1994;149(3 pt 1):818-24. https://doi.org/10.1164/ajrccm.149.3.7509706

2. Ranieri VM, Rubenfeld GD, Thompson BT, Ferguson ND, Caldwell E, Fan E, Camporota L, et al. Acute respiratory distress syndrome: the Berlin Definition. JAMA. 2012 Jun 20;307(23):2526-33. https://doi.org/10.1001/jama.2012.5669

3. Akarsu Ayazoğlu T, Onk D. Erişkin Akut Solunum Sıkıntısı Sendromu Olan Hastalarda Ekstrakorporeal Yaşam Desteği: Derleme J Turk Soc Intensive Care 2015;13:95-106.

4. The Acute Respiratory Distress Syndrome Network. Ventilation with lower tidal volumes as compared with traditional tidal volumes for acute lung injury and the acute respiratory distress syndrome. N Engl J Med 2000;342:1301-30. https://doi.org/10.1056/NEJM200005043421801 
5. Hirshberg E, Miller RR, Morris AH. Extracorporeal membrane oxygenation in adults with acute respiratory distress syndrome. Curr Opin Crit Care 2013;19:38-43. https://doi.org/10.1097/MCC.0b013e32835c2ac8

6. Lewandowski K. Extracorporeal membrane oxygenation for severe acute respiratory failure. Crit Care 2000; 4:156-68.

7. Turner DA, Cheifetz IM. Extracorporeal membrane oxygenation for adult respiratory failure. Respir Care 2013;58:1038-52. https://doi.org/10.4187/respcare.02255

8. Marasco SF, Lukas G, McDonald M, McMillan J, Ihle B. Review of ECMO (extra corporeal membrane oxygenation) support in critically ill adult patients. Heart Lung Circ 2008;17(Suppl 4):S41-7. https://doi.org/10.1016/j.hlc.2008.08.009

9. Ferguson ND, Fan E, Camporota L, Antonelli M, Anzueto $A$, Beale R, et al. The Berlin definition of ARDS: an expanded rationale, justification, and supplementary material. Intensive Care Med 2012;38:1573-82.

https://doi.org/10.1007/s00134-012-2682-1

10. Braune S, Sieweke A, Brettner F, Staudinger T, Joannidis $M$. The feasibility and safety of extracorporeal carbon dioxide removal to avoid intubation in patients with COPD unresponsive to noninvasive ventilation for acute hypercapnic respiratory failure (ECLAIR study): multicentre case-control study. Intensive Care Med 2016;429:1437-44.

https://doi.org/10.1007/s00134-016-4452-y 